\title{
The Effect of Drug Pricing on Outpatient Payments and Treatment for Three Soil-Transmitted Helminth Infections in the United States, 2010-2017
}

\author{
Heesoo Joo, ${ }^{1 \star}$ Junsoo Lee, ${ }^{1,2}$ Brian A. Maskery, ${ }^{1}$ Chanhyun Park, ${ }^{3}$ Jonathan D. Alpern, ${ }^{4,5}$ Christina R. Phares, ${ }^{1}$ \\ Michelle Weinberg, ${ }^{1}$ and William M. Stauffer ${ }^{1,5}$ \\ ${ }^{1}$ Division of Global Migration and Quarantine, U.S. Centers for Disease Control and Prevention (CDC), Atlanta, Georgia; ${ }^{2}$ Department of \\ Economics, University at Albany, SUNY, Albany, New York; ${ }^{3}$ Department of Pharmacy and Health Systems Science, Northeastern University, \\ Boston, Massachusetts; ${ }^{4}$ HealthPartners Institute, Minneapolis, Minnesota; ${ }^{5}$ Departments of Medicine and Pediatrics, University of Minnesota,
} Minneapolis, Minnesota

\begin{abstract}
The price of certain antiparasitic drugs (e.g., albendazole and mebendazole) has dramatically increased since 2010. The effect of these rising prices on treatment costs and use of standard of care (SOC) drugs is unknown. To measure the impact of drug prices on overall outpatient cost and quality of care, we identified outpatient visits associated with ascariasis, hookworm, and trichuriasis infections from the 2010 to 2017 MarketScan Commercial Claims and Encounters and Multi-state Medicaid databases using Truven Health MarketScan Treatment Pathways. Evaluation was limited to members with continuous enrollment in non-capitated plans 30 days prior, and 90 days following, the first diagnosis. The utilization of SOC prescriptions was considered a marker for quality of care. The impact of drug price on the outpatient expenses was measured by comparing the changes in drug and nondrug outpatient payments per patient through Welch's two sample $t$-tests. The total outpatient payments per patient (drug and nondrug), for the three parasitic infections, increased between 2010 and 2017. The increase was driven primarily by prescription drug payments, which increased 20.6-137.0 times, as compared with nondrug outpatient payments, which increased 0.3-2.2 times. As prices of mebendazole and albendazole increased, a shift to alternative SOC and non-SOC drug utilization was observed. Using parasitic infection treatment as a model, increases in prescription drug prices can act as the primary driver of increasing outpatient care costs. Simultaneously, there was a shift to alternative SOC, but also to non-SOC drug treatment, suggesting a decrease in quality of care.
\end{abstract}

\section{INTRODUCTION}

Globally, soil-transmitted helminth (STH) infections are some of the most common infections found in humans. More than one billion people are infected by at least one of the three most common STH: ascariasis, hookworm, and trichuriasis. ${ }^{1}$ These infections were estimated to result in 4.98 million years lost to disability in $2010 .^{2}$ These STH infections have been decreasing overall because of the availability of cheap and effective drug treatment and through successful prevention campaigns, including mass preventative therapy programs. $^{3}$

In the United States, these three STH infections are relatively uncommon. ${ }^{4}$ Albendazole and mebendazole are drugs of choice recommended by the U.S. Centers for Disease Control and Prevention (CDC) to treat all three infections. ${ }^{5-7}$ These drugs have seen some of the greatest price increases of drugs on the U.S. market. $^{8,9}$ Because the manufacturer, Teva Pharmaceuticals, discontinued producing mebendazole for (non-safety-related) business reasons, mebendazole was withdrawn from the U.S. market in 2011 until 2016, when it was reintroduced at around 80 times increased price..$^{9,10}$ There are limited alternative drugs available in the United States, including ivermectin for ascariasis and trichuriasis, and pyrantel pamoate for hookworm. ${ }^{5-7}$ These alternatives were less expensive than albendazole or mebendazole during 2010-2017. ${ }^{11}$

There is conflicting information on the impact of drug prices on the overall cost of care in the United States and limited direct data on how large drug price increases affect overall cost to patients and insurers, access to drugs, and prescribing

\footnotetext{
*Address correspondence to Heesoo Joo, Division of Global Migration and Quarantine, U.S. Centers for Disease Control and Prevention, 1600 Clifton Rd NE, MS H16-4, Atlanta, GA 30329. E-mail: hjoo@cdc.gov
}

behaviors of health professionals. Although data on treatment costs associated with treating parasitic infections with these drugs in the United States are limited, ${ }^{12,13}$ these three infections, coupled with the limited treatment options, can offer a window into the impact of price increases into the overall cost of care to patients and insurers and on the prescribing behavior of clinicians. This evaluation attempts to measure the effect of increased costs for standard of care (SOC) drugs used for STH treatment on the use of an SOC drug, and to estimate the impact of drug payments on the overall outpatient medical payments for care in the United States.

\section{MATERIALS AND METHODS}

The IBM ${ }^{\circledR}$ MarketScan ${ }^{\circledR}$ (MarketScan) Commercial Claims and Encounters (CCAE) Database and MarketScan Multi-state Medicaid Database (IBM Watson Health, Ann Arbor, MI) were used for the analyses. The MarketScan CCAE database consists of medical and drug payment data from a convenience sample of employers and health plans. The MarketScan Medicaid database includes similar data for a convenience sample of 23 million Medicaid-covered individuals between 2009 and 2018 from 10 to 13 geographically dispersed states. States in the database may vary by year. Data extraction for patient encounters from 2010 to 2017 was performed using an online tool, Truven Health MarketScan Treatment Pathways. ${ }^{14}$

\section{Selection criteria were (Supplemental Appendix Figures} 1 and 2):

1. A primary diagnosis of a single infection with ascariasis, hookworm (ancylostomiasis or necatoriasis), or trichuriasis from February 1, 2010 through December 31, 2017. International Classification of Diseases, Ninth Revision, Clinical Modification [ICD-9-CM] codes were used for data before September 30, 2015, and ICD-10-CM codes were 
used for patients after this date. International Classification of Diseases, Ninth Revision, Clinical Modification and ICD10-CM codes for each parasitic disease are shown in Supplemental Appendix Table 1. Patients for whom a diagnosis was labeled as "rule-out" (tested and confirmed not to have the condition) were excluded.

2. Insurance coverage by private insurance or Medicaid only. Medicare coverage (either partial or full) was excluded. Because Medicare payment data were not available, we excluded patients enrolled in employer-sponsored Medicare Supplemental plans and those 65 years or older at diagnosis (and thus likely to have access to Medicare).

3. Continuous enrollment in MarketScan CCAE or Medicaid from 30 days before the date of the first diagnosis to 90 days following the date. We chose this window with the assumption that it would likely capture visits associated with the infection. All payments associated with STH treatment in this window were included to estimate average payments per patient in the analyses.

4. Non-capitated insurance. Patients with capitated insurance plans were excluded because payments to healthcare providers are fixed in capitated plans and independent of the amount of care, or cost of any single visit.

5. A single infection with ascaris, or hookworm, or trichuris. We excluded patients diagnosed with more than one of these three parasites; we additionally excluded patients who were also diagnosed with schistosomiasis or strongyloidiasis. Coinfected patients might have had different and more complex clinical presentations; greater variability in the number of outpatient visits, clinician prescribing patterns, and outpatient expenditures; and higher billing due to multiple complaints and diagnoses. Less than $2 \%$ of patients were diagnosed with such coinfections (Supplemental Appendix Tables 1 and 2).

6. Outpatient treatment only. Patients with inpatient visits were excluded because the pharmaceutical claims during inpatient visits were not available in MarketScan. Inpatient visits were uncommon $(<4 \%)$.

There were 1,692 patients with outpatient diagnosis codes of ascariasis, 2,355 patients with hookworm, and 197 patients with trichuriasis who satisfied these six criteria from 2010 to 2017 in the MarketScan CCAE database (Supplemental Appendix Figure 1), representing individuals with private insurance. An additional 600 patients with outpatient diagnosis codes for ascariasis, 337 patients with hookworm, and 109 patients with trichuriasis from 2010 to 2017 were identified in the MarketScan Multi-state Medicaid database, representing individuals with public insurance (Supplemental Appendix Figure 2).

The prescription SOC drugs for each infection in the current analyses are defined by following the CDC's recommended drugs for treating each infection (Table 1). ${ }^{5-7}$ Drugs not recommended for a given infection by the CDC were defined as non-SOC drugs. Drugs considered SOC for ascariasis and trichuriasis include albendazole, mebendazole, and

TABLE 1

Drugs, dosages, and cure rates for treatment of the selected soil-transmitted helminth

\begin{tabular}{|c|c|c|c|c|c|c|}
\hline $\begin{array}{l}\text { Parasitic } \\
\text { diseases }\end{array}$ & $\begin{array}{l}\text { Drug (active } \\
\text { ingredient) }\end{array}$ & Dosage $^{5-7}$ & $\begin{array}{l}\text { Estimated cure } \\
\text { rate }(\%)^{15}\end{array}$ & $\begin{array}{l}\text { Average wholesale price of treatment } \\
\text { for a } 150-\text { pound ( } 68 \mathrm{~kg} \text { adult on } \\
\text { January } 1,2010 \text { (US dollar) }^{11}\end{array}$ & $\begin{array}{l}\text { Average wholesale price of treatment } \\
\text { for a 150-pound (68 kg) adult in on } \\
\text { December } 31,2017 \text { (US dollar) }\end{array}$ & $\begin{array}{l}\text { Standard } \\
\text { of care by } \\
\text { the CDC }\end{array}$ \\
\hline \multirow[t]{4}{*}{ Ascariasis } & Albendazole & 400 mg orally once & 96.5 (94.4-97.9) & $\begin{array}{l}3.16 \text { (product name: } \\
\text { Albenza) }\end{array}$ & $\begin{array}{l}438.77 \text { (product name: } \\
\text { Albenza) }\end{array}$ & Yes \\
\hline & Mebendazole & $\begin{array}{l}100 \text { mg orally twice daily } \\
\text { for } 3 \text { days or } 500 \mathrm{mg} \\
\text { orally once }\end{array}$ & $96.8(93.3-98.5)$ & $\begin{array}{l}31.92 \text { (product name: } \\
\text { mebendazole; } 600 \text { mg) }\end{array}$ & $\begin{array}{l}\text { 2,656.80 (product name: } \\
\text { Emverm; } 600 \mathrm{mg} \text { ) }\end{array}$ & Yes \\
\hline & Ivermectin & $\begin{array}{l}150-200 \mathrm{mcg} / \mathrm{kg} \text { orally } \\
\text { once }\end{array}$ & $97.3(85.7-99.5)$ & $\begin{array}{l}22.33 \text { (product name: } \\
\text { Stromectol; } 12 \mathrm{mg} \text { ) }\end{array}$ & $\begin{array}{l}21.10 \text { (product name: } \\
\text { Stromectol and } \\
\text { ivermectin; } 12 \mathrm{mg} \text { ) }\end{array}$ & Yes \\
\hline & $\begin{array}{l}\text { Pyrantel } \\
\text { pamoate }\end{array}$ & $\begin{array}{l}\text { Not recommended by } \\
\text { the CDC }\end{array}$ & $93.0(86.7-96.4)$ & $\begin{array}{c}\text { N/A (average price of } 30 \\
\text { mL package: } \$ 7.07 \text { ) }\end{array}$ & $\begin{array}{c}\text { N/A (average price of } 30 \\
\text { mL package: } \$ 6.30 \text { ) }\end{array}$ & No \\
\hline \multirow[t]{4}{*}{ Hookworm } & Albendazole & 400 mg orally once & $78.5(71.5-84.2)$ & $\begin{array}{l}3.16 \text { (product name: } \\
\text { Albenza) }\end{array}$ & $\begin{array}{l}438.77 \text { (product name: } \\
\text { Albenza) }\end{array}$ & Yes \\
\hline & Mebendazole & $\begin{array}{c}100 \text { mg orally twice a } \\
\text { day for } 3 \text { days or } \\
500 \text { mg orally once }\end{array}$ & $41.6(30.7-53.3)$ & $\begin{array}{l}31.92 \text { (product name: } \\
\text { mebendazole; } 600 \text { mg) }\end{array}$ & $\begin{array}{l}\text { 2,656.80 (product name: } \\
\text { Emverm; } 600 \mathrm{mg} \text { ) }\end{array}$ & Yes \\
\hline & Ivermectin & $\begin{array}{l}\text { Not recommended by } \\
\text { the CDC }\end{array}$ & $24.3(11.5-44.3)$ & $\begin{array}{l}\text { N/A ( } \$ 5.58 \text { per } 3 \text { mg tablet; } \\
\text { product name: } \\
\text { Stromectol) }\end{array}$ & $\begin{array}{l}\text { N/A ( } \$ 5.28 \text { per } 3 \text { mg tablet; } \\
\text { Product name: } \\
\text { Stromectol and } \\
\text { ivermectin) }\end{array}$ & No \\
\hline & $\begin{array}{l}\text { Pyrantel } \\
\text { pamoate }\end{array}$ & $\begin{array}{l}11 \mathrm{mg} / \mathrm{kg} \text { (up to a } \\
\text { maximum of } 1 \mathrm{~g} \text { ) } \\
\text { orally daily for } 3 \text { days }\end{array}$ & $52.6(39.4-65.4)$ & $\begin{array}{l}7.07 \text { (average price of } 30 \\
\text { mL package) }\end{array}$ & $\begin{array}{l}6.30 \text { (average price of } 30 \\
\text { mL package) }\end{array}$ & Yes \\
\hline \multirow{4}{*}{$\begin{array}{l}\text { Trichuriasis } \\
\text { (whipworm } \\
\text { infection) }\end{array}$} & Albendazole & $400 \mathrm{mg}$ orally for 3 days & $83(73-93)^{16}$ & $\begin{array}{l}9.48 \text { (product name: } \\
\text { Albenza) }\end{array}$ & $\begin{array}{l}\text { 1,316.31 (product name: } \\
\text { Albenza) }\end{array}$ & Yes \\
\hline & Mebendazole & $\begin{array}{l}100 \text { mg orally twice a } \\
\text { day for } 3 \text { days }\end{array}$ & $44.4(30.8-59.0)$ & $\begin{array}{l}31.92 \text { (product name: } \\
\text { mebendazole; } 600 \text { mg) }\end{array}$ & $\begin{array}{l}\text { 2,656.80 (product name: } \\
\text { Emverm; } 600 \mathrm{mg} \text { ) }\end{array}$ & Yes \\
\hline & Ivermectin & $\begin{array}{l}200 \mathrm{mcg} / \mathrm{kg} / \text { day orally } \\
\text { for } 3 \text { days }\end{array}$ & 32.1 (16.3-53.5) & $\begin{array}{r}78.16 \text { (product name: } \\
\text { Stromectol; } 42 \mathrm{mg} \text { ) }\end{array}$ & $\begin{array}{l}73.86 \text { (product name: } \\
\text { Stromectol and } \\
\text { ivermectin; } 42 \mathrm{mg} \text { ) }\end{array}$ & Yes \\
\hline & $\begin{array}{l}\text { Pyrantel } \\
\text { pamoate }\end{array}$ & $\begin{array}{l}\text { Not recommended by } \\
\text { the CDC }\end{array}$ & $23.4(11.7-41.1)$ & $\begin{array}{c}\text { N/A (average price of } 30 \\
\text { mL package: } \$ 7.07 \text { ) }\end{array}$ & $\begin{array}{c}\text { N/A (average price of } 30 \\
\text { mL package: } \$ 6.30)\end{array}$ & No \\
\hline
\end{tabular}

Notes: We include drugs for oral usage only and excludd repackagers to estimate average wholesale price of each active ingredient. If multiple products are available in the market, we calculated the simple average of average wholesale prices. N/A stands for "not available" because the recommended amount of drug usage for treating a 150 -pound ( $68 \mathrm{~kg}$ ) adult is not available and the drug is not recommended by the CDC. Thus, we reported average wholesale unit price instead of average wholesale price of treatment for a 150 -pound ( $68 \mathrm{~kg})$ adult. 
ivermectin (doses vary between ascariasis and trichuriasis). Drugs considered SOC for hookworm include albendazole, mebendazole, and pyrantel pamoate. Information on indication and dosing, and other product information for albendazole, mebendazole, ivermectin, and pyrantel pamoate are reported in Table 1.

In addition, Table 1 includes estimated effectiveness at the recommended dosage for each SOC and non-SOC drug against each infection, and the average wholesale price for the recommended dosage in 2010 and 2017. In summary, albendazole, mebendazole, and ivermectin are all effective against ascariasis. ${ }^{15}$ Albendazole is the most effective against hookworm, although mebendazole is another prescription SOC drug. ${ }^{6,15}$ Ivermectin is less effective against hookworm and is not an SOC drug for this infection. ${ }^{6,15}$ Trichuriasis is the most difficult of the infections to treat and requires longer durations of treatment with single drugs or drug combinations for appropriate treatment. ${ }^{7,15,16}$

Albendazole is an off-patent drug in the United States. ${ }^{10}$ However, a single pharmaceutical company has distributed albendazole and mebendazole in the United States since 2013, and average wholesale prices for albendazole and mebendazole have increased dramatically since $2010 .^{10}$ Average wholesale prices for albendazole increased from $\$ 3.16$ (400 mg for ascariasis and hookworm treatment) and $\$ 9.48$ (1,200 mg for trichuriasis treatment) on January 1 , 2010 to $\$ 438.77$ and $\$ 1,316.31$, respectively, on December 31, 2017 (Table 1). ${ }^{11}$ The wholesale price for albendazole was 13,785\% higher on December 31, 2017 than on January 1, 2010. During the same period, average wholesale prices for mebendazole increased by $8,223 \%$ from $\$ 31.92(200$ $\mathrm{mg} /$ day for 3 days for all three infections) to $\$ 2,656.80,{ }^{11}$ whereas ivermectin decreased by $6 \%$ from $\$ 22.33$ to $\$ 21.10$ (Table 1). ${ }^{11}$

Outcome measures included utilization of SOC and nonSOC prescription drugs, and total outpatient payments by period, payer, and insurance type. Total outpatient payments were separated into payments for drugs versus all other nondrug outpatient treatment payments (e.g., office visits and diagnostic tests). The patients' out-of-pocket (OOP) payments were also separately reported. We analyzed payments for four periods: 2010-2011, 2012-2013, 2014-2015, and 2016-2017.

Changes in the utilization of the prescription SOC drugs and increases in total outpatient payments over time were measured using Welch's $t$-tests. ${ }^{17}$ The prescription SOC drug utilization for one period $(t)$ was compared with the utilization for a period just before the chosen period $(t-1)$. For instance, the utilization of the prescription SOC drugs in 2012-2013 was compared with the utilization of the prescription SOC drugs in 2010-2011. For drug and nondrug outpatient payments, the average payments for one period $(t)$ were compared with the average payments for a period just before the chosen period $(t-1)$. $P$-values equal to or less than 0.05 from the Welch's $t$ test were used as a threshold of rejecting the null hypothesis.

Welch's $t$-tests were also used to examine whether the utilization of each prescription drug increased or decreased as the prices of albendazole and mebendazole were increasing. This test was also used to measure the impact of availability of mebendazole, which was off the market between 2011 and 2016 , on the utilization of each of the prescription drugs (e.g., was an SOC or non-SOC drug substituted for mebendazole).
Special attention was given to the use of ivermectin for hookworm infection, a non-SOC drug.

\section{RESULTS}

The overall fraction of patients using prescription drugs, and those using albendazole, mebendazole, or ivermectin specifically, varied by type of insurance and parasitic infection. The overall percentage of persons with ascariasis or trichuriasis treated with SOC or non-SOC prescription drugs significantly differed between those on private insurance and those on Medicaid according to Pearson's chi-squared tests; for ascariasis, the percentages were $59 \%(1,004$ of 1,692$)$ of those on private insurance compared with $72 \%$ (432 of 600 ) on Medicaid $\left(X^{2}[1, N=1,712]=30.3, P<0.01\right)$, and for trichuriasis infection, 52\% (102 of 197) and 74\% (81 of 109) $\left(X^{2}[1, N=\right.$ $306]=14.8, P<0.01)$, respectively (Supplemental Appendix Figures 1 and 2). For hookworm infection, the percentages were $62 \%(1,462$ of 2,355$)$ of those with private insurance and $58 \%$ (195 of 337) of those with Medicaid $\left(X^{2}[1, N=2,692]=2.2\right.$, $P=0.14)$. Excluding hookworm patients treated with ivermectin (not SOC for this infection), the proportion treated with SOC prescription drugs (i.e., albendazole or mebendazole) was only $33 \%(779$ of 2,355$)$ for those with private insurance and $42 \%$ (140 of 337) for those with Medicaid (X2 [1, N=2,692] = 9.4, $P<$ $0.01)$. The utilization of SOC prescription drugs significantly decreased for privately insured patients with hookworm infections for each interval from 2010-2011 to 2012-2013 to 2014-2015 (Figure 1 and Supplemental Appendix Table 2). The decreasing SOC treatment for hookworm for those who had private insurance was partially explained by an increasing percentage of patients being treated with the nonSOC drug ivermectin (Figure 1 and Supplemental Appendix Table 2).

Average total outpatient payments per patient who received prescription SOC drugs significantly increased over time based on Welch's $t$-test results (Supplemental Appendix Table 3). For patients with private insurance, average total payments per patient increased between $2010-2011$ and $2016-2017$ by 5.3 times for ascaris (from \$189.39 [95\% Cls: \$165.19-\$213.60] to $\$ 1,197.26$ [95\% Cl: \$876.48-\$1,518.04]), 8.8 times for hookworm infection (from $\$ 193.22$ [95\% Cl: $\$ 169.71-\$ 216.73$ ] to $\$ 1,898.92$ [95\% Cl: $\$ 1,538.37-\$ 2,259.47])$, and 4.3 times for trichuriasis (from \$358.23 [95\% Cl: \$147.48-\$568.97] to $\$ 1,553.19$ [95\% Cl: $\$ 993.71-\$ 2,112.66]$ ) (Figure 1 and Supplemental Appendix Table 3). For patients with Medicaid, average total payments per patient increased by 6.9 times for ascariasis (from $\$ 120.85$ [95\% Cl: $\$ 109.83-\$ 131.87]$ to \$952.52 [95\% Cl: \$728.10-\$1,176.94]), 9.0 times for hookworm (from \$132.97 [95\% Cl: \$109.28-\$156.65] to \$1,328.54 [95\% Cl: $\$ 1,080.08-\$ 1,577.00]$ ), and 28.1 times for trichuriasis (from $\$ 111.40$ [95\% Cl: $\$ 79.39-\$ 143.40]$ to $\$ 3,244.63$ [95\% Cl: \$1,728.10-\$4,761.16]) between 2010-2011 and 2016-2017.

Between 2010-2011 and 2016-2017, average OOP payments per patient with private insurance for prescription SOC drugs increased by 1.4 (from $\$ 78.08$ [95\% Cl: \$59.94-\$96.21] to $\$ 187.51$ [95\% Cl: $\$ 143.67-\$ 231.35]$ ) for treatment of ascaris, and 1.8 times (from $\$ 70.22$ [95\% Cl: \$60.64-\$79.79] to \$195.96 [95\% Cl: \$158.42-\$233.50]) for hookworm (Supplemental Appendix Table 3). For trichuriasis, the minimum OOP payments were reported in 2016-2017 (\$82.10 [95\% Cl: $\$ 43.89-\$ 120.31])$, whereas the maximum was reported in 

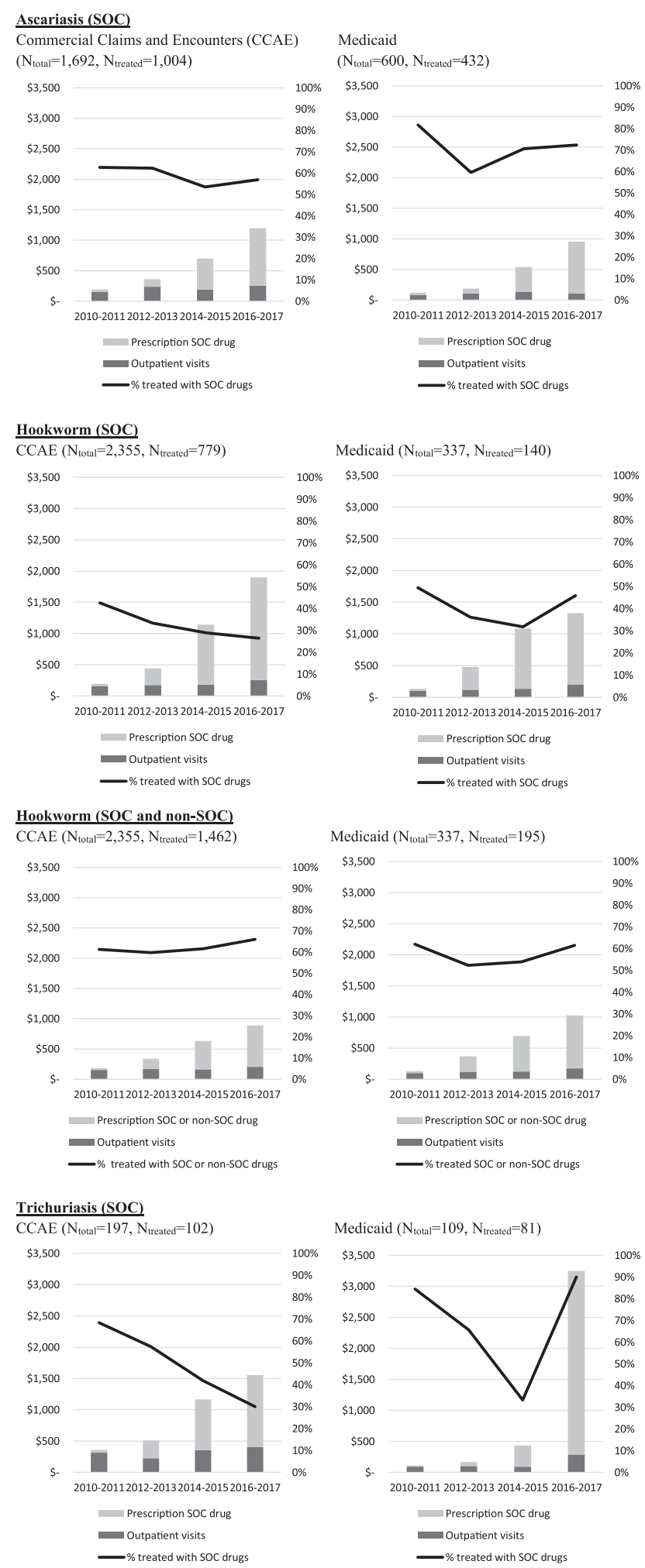

FIGURE 1. Overall outpatient payment and percentage of patients treated by prescription $\mathrm{SOC}$ or prescription non-SOC drugs by period. $\mathrm{SOC}=$ standard of care.

2014-2015 (\$197.70 [95\% Cl: \$62.36-\$333.03]). A majority of patients with Medicaid who were treated with prescription SOC drugs reported zero OOP payment $(87 \%$ with ascariasis, $79 \%$ with hookworm, and $89 \%$ with trichuriasis).
Although the total nondrug outpatient payments increased for all three infections between 2010-2011 and 2016-2017, the payments for $\mathrm{SOC}$ prescription drugs increased at a much faster rate. For ascariasis, the total nondrug outpatient payments increased by 0.6 times from 2010-2011 to 2016-2017 in those privately insured, and by 0.4 times for patients with Medicaid, whereas the prescription SOC drug payments over the same period increased by 26.8 times and 20.6 times, respectively. For hookworm, total nondrug outpatient payments increased 0.6 times in privately insured patients and doubled for those on Medicaid, whereas prescription SOC drug payments increased by 49.2 and 31.9 times, respectively. Similarly, for trichuriasis, nondrug outpatient payments increased by 0.3 in privately insured patients and 2.2 times for patients on Medicaid, whereas prescription SOC drug payments increased by 26.8 and 137 times.

For each infection, the fraction of patients treated with each prescription drug or with a combination of drugs is shown in Figure 2. Mebendazole was removed from the market in 2011, and for all three infections, there was the substitution from mebendazole to albendazole between 2010-2011 and 2014-2015 as the available drug stocks were used (Supplemental Appendix Table 4). This trend was reversed when mebendazole returned to the market in 2016. However, mebendazole reentered the market with a substantially increased price, and utilization did not return to the usage levels observed during 2010-2011, when mebendazole and albendazole were both relatively inexpensive.

The fraction of private insured patients receiving ivermectin significantly increased for ascariasis (SOC) and hookworm infection (non-SOC) between the 2010-2011 and 2016-2017 coincident with the increasing price of mebendazole and albendazole (Supplemental Appendix Table 4). For instance, ivermectin-only treatment for ascariasis patients with private insurance was $1 \%$ in 2010-2011 but increased with each successive interval, reaching $21 \%$ in 2016-2017. In 20102011 , the payment for albendazole-only treatment was $\$ 20$ and mebendazole-only treatment $\$ 35$, whereas by the period of 2016-2017, the average albendazole-only treatment payment rose to $\$ 655$, and mebendazole-only treatment to $\$ 2,111$. Ivermectin pricing decreased from $\$ 29$ to $\$ 23$ over the same period (Supplemental Appendix Table 4).

\section{DISCUSSION}

The average total medical outpatient payments per person diagnosed with ascariasis, hookworm, or trichuriasis increased by between 4 and 28 times over the study period. The increased cost of outpatient care for these three infections was driven almost entirely by the rising drug price of albendazole and mebendazole. Whereas the Consumer Price Index for prescription drugs from the Bureau of Labor Statistics increased by $27.4 \%$ between 2010 (\$92.7) and 2017 (\$118.1), ${ }^{18}$ the prescription drug payments for the two most effective SOC treatments for these neglected parasitic infections increased by between $3,115 \%$ and $8,744 \%$. The statistically significant increases in prescription $\mathrm{SOC}$ drug payments were found to be the main drivers of the overall outpatient medical payments for patients with private or Medicaid insurance.

The percentages of patients prescribed appropriate SOC treatment with private insurance for all three infections over the study period were consistently less than $70 \%$ and, in the 


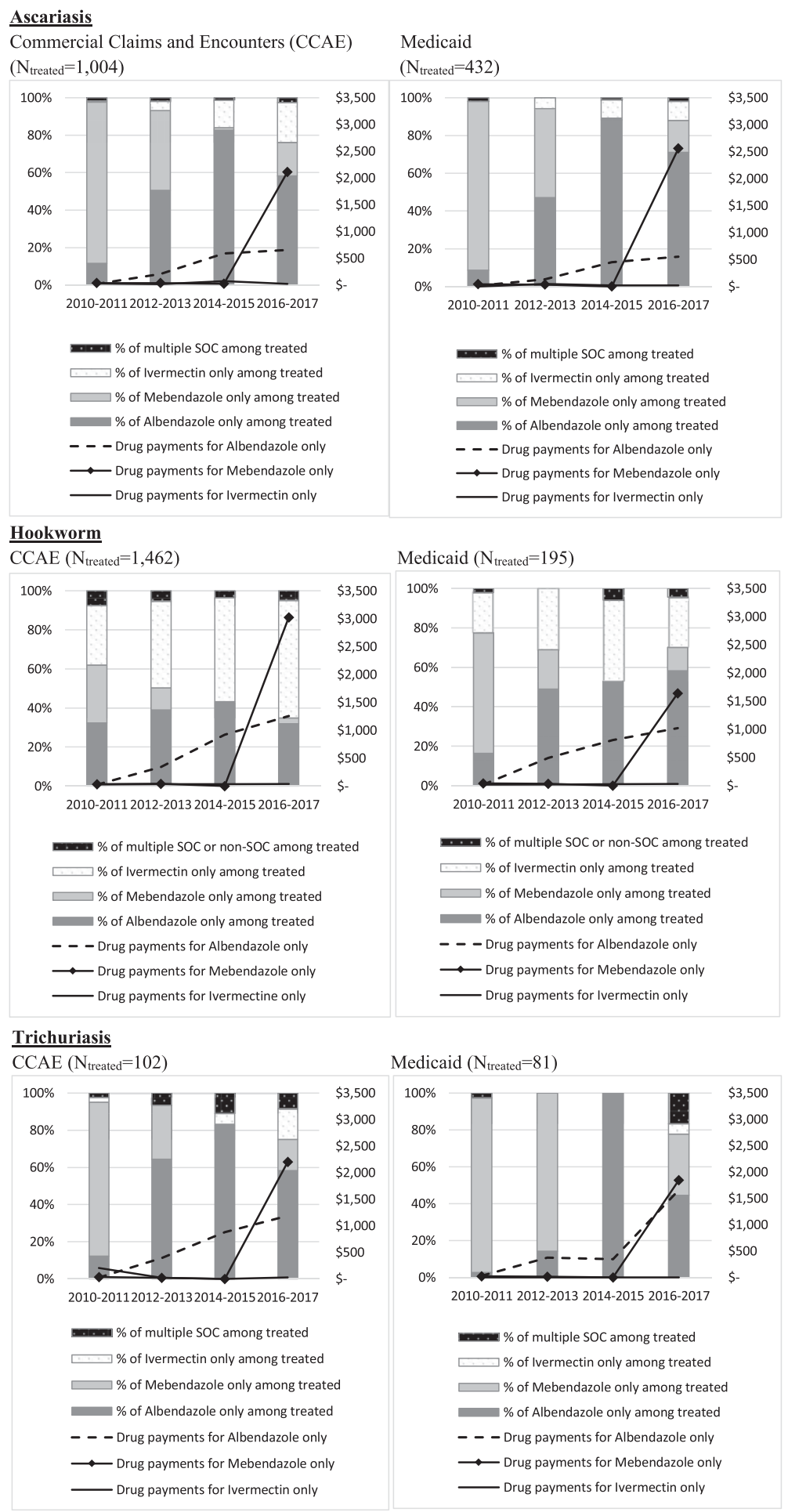

Notes: SOC stands for standard of care. Ivermectin is non-SOC prescription drug for hookworm. $\mathrm{N}_{\text {treated }}$ represent numbers of samples with prescription SOC drug treatment.

FIGURE 2. Fraction of patients treated with each prescription drug or with a combination of drugs among those who were treated.

case of hookworm diagnosed in those with private insurance, less than $30 \%$ of patients receiving an SOC prescription drug (Figure 1). This rate of appropriate treatment is disturbingly low.

Ivermectin is an SOC drug for ascariasis. Utilization of ivermectin for ascariasis in privately insured patients increased over time as the cost of albendazole and mebendazole dramatically increased. This substitution would not be considered inferior quality of care because all three prescription SOC drugs have been shown to have > 95\% effectiveness (Table 1$)^{15}$ and would have been cost-saving, given that in 2016-2017, the ivermectin-only treatment total outpatient payment averaged $\$ 207$ per patient with private 
insurance while albendazole-only and mebendazole-only treatment total outpatient payments were $\$ 916$ and $\$ 2,428$, respectively.

Ivermectin is a non-SOC drug for intestinal hookworms (ancylostomiasis or necatoriasis). However, we found high (20-30\%) use of ivermectin before the price increase of albendazole and mebendazole in 2010-11, which may be partially explained by the fact that ivermectin is an SOC drug for a zoonotic hookworm species, cutaneous larva migrans. In addition, we observed the same shift over time toward increased utilization of ivermectin in privately insured patients as the cost of albendazole and mebendazole increased. This shift is concerning because this likely represents decreased quality of care because ivermectin-only is estimated to only be approximately $24.3 \%$ effective (compared with albendazoleonly at $78.5 \%$ and mebendazole-only at $41.6 \%){ }^{15}$

The shift to ivermectin-only treatment in patients with private insurance occurred as there was a substantial rise in the OOP costs for SOC treatment. During 2010-2011, ivermectinonly treatment was used $30 \%$ of the time for hookworm in patients with private insurance and $20 \%$ of the time in Medicaid patients (Supplemental Appendix Table 4). By 2016-2017, as the price of albendazole and mebendazole increased dramatically, ivermectin-only treatment for hookworm infection increased to $60 \%$ of drug prescriptions for patients with hookworm diagnoses with private insurance, while remaining at $25 \%$ for those on Medicaid. Over the same period, the OOP payments by patients for an SOC drug for hookworm increased from $\$ 16.97$ to $\$ 116.23$ for those with private insurance but remained near zero for those on Medicaid.

Trichuris is more complicated to assess, given that longer durations of treatment or drug combinations are usually required to cure the infection. However, by 2016-2017, 17\% of privately insured patients received ivermectin-only treatment for trichuriasis (Supplemental Appendix Table 4). Although not a statistically significant increase over the previous period, this drug regimen would not be considered adequate because effectiveness is estimated to be at $32.1 \%$, even though ivermectin is still listed as an SOC drug. ${ }^{15}$

Other factors affecting the overall low rate of SOC treatment for STH infections could include reporting errors in the databases and the availability of over-the-counter (OTC) treatment for certain infections (e.g., hookworm). Also, the increase of OOP payments could reduce rates of SOC treatment for STH infections. For instance, Medicaid patients were more likely to be treated with prescription SOC drugs than those who were covered by private insurance with some exceptions. This may due to the differences in OOP drug payments between Medicaid and private insurance because more than $80 \%$ of patients with these infections on Medicaid had zero OOP drug payment while OOP payments for private insurance holders increased significantly. This may also reflect that providers who see more Medicaid patients may be more familiar with infections that affect marginalized populations.

This study had multiple limitations. Because of limited data available in MarketScan, we could not estimate payments for individuals with diagnosis codes for these three STH infections who did not have prescription drug claims. These patients who were not included may have 1) not been infected with these STH infections, 2) been treated without drug claims, or 3) have forgone treatment. Because we excluded "ruled- out" diagnoses, the chances of the person not truly being infected were minimized.

For treatment without drug claims, there are multiple possibilities. We would have not captured patients who paid in full for drugs without using health insurance. This could occur if the health insurer refused to pay or the patient had a high deductible plan. In this case, they may have chosen to find drugs through alternative routes such as to purchase them overseas where drugs are a fraction of the cost, ${ }^{19}$ purchased over the internet or even purchase from veterinary sources. An additional reason they may have had treatment without drug claims is that the patients may have purchased OTC SOC or non-SOC drugs. OTC drug purchases do not require a prescription and are not covered by health insurance. As a result, patients treated with OTC drugs would not be captured in MarketScan. The only OTC SOC drug for these three infections is pyrantel pamoate, which remained relatively inexpensive over the study period. ${ }^{11}$ Pyrantel pamoate has reported effectiveness against both ascariasis and hookworm, ${ }^{15}$ although it is only recommended for treatment of hookworm by the CDC. ${ }^{6}$ The fraction of hookworm patients treated with SOC prescription drugs was lower than the fraction of ascariasis or trichuriasis patients treated with SOC prescription drugs, which may be due to the use of this OTC SOC drug. Only $42 \%$ of hookworm patients with Medicaid received prescription SOC drugs. Even after we considered ivermectin, which is non-SOC for hookworm, the treatment rate for hookworm patients with Medicaid (58\%) is still lower than the treatment rates for ascariasis $(72 \%)$ or trichuriasis (74\%) with Medicaid. If we assume that half of these hookworm patients who did not receive prescription SOC drugs were treated by OTC SOC drugs, the fraction treated would increase to $71 \%$, which is similar to the treatment rates of ascariasis and trichuriasis. In some states, Medicaid prior authorization policies require the usage of pyrantel pamoate for hookworm. ${ }^{20}$

Other limitations included the assumption that all costs would be incurred within 90 days after the first parasitic infection diagnosis (some infections may have incurred costs after the 90 days), the evaluation was limited to those with either private insurance or Medicaid (those without insurance were not captured), and that the states providing Medicaid data to MarketScan varied over the analysis period and may not be representative of all Medicaid programs. In addition, as with all studies that rely on claims data, coding errors may influence our results. Also, ICD codes may not confirm the parasitic infections, although we excluded rule-out diagnosis. This may cause the underestimation of SOC or non-SOC drug treatment rates.

\section{CONCLUSION}

The dramatic increase in the price of albendazole and mebendazole is the major driver for the increase in outpatient payments for treatment of these STH infections in the United States for both Medicaid and privately insured patients. The increases of the drug price and the OOP patient expenses coincided with a shift from more expensive SOC drugs to less expensive SOC drugs. However, of concern was a statistically significant shift in the treatment of hookworm from SOC treatment to non-SOC prescription drug treatment. This shift was apparent in those with private insurance coverage and 
was associated in increased OOP payments. Although this evaluation was limited to STH treatment in the United States, the findings suggest dramatic drug price increases may be primarily responsible for increased outpatient cost and may have deleterious effects on quality of care.

Received November 10, 2020. Accepted for publication January 7 , 2021.

Published online March 8, 2021.

Note: Supplemental appendix tables and figure appear at www. ajtmh.org.

Authors' addresses: Heesoo Joo, Brian A. Maskery, Christina R. Phares, and Michelle Weinberg, Division of Global Migration and Quarantine, U.S. Centers for Disease Control and Prevention (CDC), Atlanta, GA, E-mails: hjoo@cdc.gov, wqm7@cdc.gov, ctp7@cdc.gov, and mpw5@cdc.gov. Junsoo Lee, Department of Economics, University at Albany, SUNY, Albany, NY, E-mail: jlee38@albany.edu. Chanhyun Park, Department of Pharmacy and Health Systems Science, School of Pharmacy, Bouvé College of Health Sciences, Northeastern University, Boston, MA, E-mail: c.park@northeastern.edu. Jonathan D. Alpern, HealthPartners Institute, Minneapolis, MN, E-mail: alper054@ umn.edu. William M. Stauffer, Division of Infectious Diseases and International Medicine, Departments of Medicine and Pediatrics, University of Minnesota, Minneapolis, MN, E-mail: stauf005@umn.edu.

This is an open-access article distributed under the terms of the Creative Commons Attribution (CC-BY) License, which permits unrestricted use, distribution, and reproduction in any medium, provided the original author and source are credited.

\section{REFERENCES}

1. Keiser J, Utzinger J, 2019. Community-wide soil-transmitted helminth treatment is equity-effective. Lancet 393: 2011-2012.

2. Pullan RL, Smith JL, Jasrasaria R, Brooker SJ, 2014. Global numbers of infection and disease burden of soil transmitted helminth infections in 2010. Parasit Vectors 7: 37.

3. The United States Agency for International Development (USAID), Neglected Tropical Diseases Program: Soil Transmitted Helminths: Control of Soil-Transmitted Helminth Infections can be Achieved Through Regular Mass Drug Administration (MDA) with a Single Dose Albendazole or Mebendazole. Available at: https://www.neglecteddiseases.gov/usaid-target-diseases/ soil-transmitted-helminths. Accessed May 12, 2020.

4. Centers for Disease Control and Prevention, Global Health, Division of Parasitic Diseases and Malaria, 2013. Parasites - Soiltransmitted helminths. Available at: https://www.cdc.gov/ parasites/sth/index.html. Accessed September 16, 2020.

5. Division of Parasitic Diseases, US CDC, 2019. Parasites - Ascariasis. Resources for Health Professionals. Available at: https:// www.cdc.gov/parasites/ascariasis/health_professionals/index. html\#tx. Accessed October 2, 2019.
6. Division of Parasitic Diseases, US CDC, 2019. Parasites - Hookworm. Resources for Health Professionals. Available at: https:// www.cdc.gov/parasites/hookworm/health_professionals/index. html\#tx. Accessed April 14, 2020.

7. Division of Parasitic Diseases, US CDC, 2019. Parasites - Trichuriasis. Resources for Health Professionals. Available at: https://www. cdc.gov/parasites/whipworm/health_professionals/index.html. Accessed April 14, 2020.

8. Alpern JD, Zhang L, Stauffer WM, Kesselheim AS, 2017. Trends in pricing and generic competition within the oral antibiotic drug market in the United States. Clin Infect Dis 65: 1848-1852.

9. Crow D, 2016. US drugmaker charges 200 times UK price for common worm pill. Available at: https://www.ft.com/content/ f0080fe4-c3ad-11e6-9bca-2b93a6856354. Accessed May 12, 2020.

10. Alpern JD, Stauffer WM, Kesselheim AS, 2014. High-cost generic drugs--implications for patients and policymakers. $N$ Engl $J$ Med 371: 1859-1862.

11. IBM Micromedex [database online], 2019. Active Ingredient: Albendazole, mebendazole, ivermectin. RED BOOK Online. Truven Health Analytics/IBM Watson Health. Available at: https://www.micromedexsolutions.com. Accessed November 21, 2019.

12. Muennig P, Pallin D, Challah C, Khan K, 2004. The costeffectiveness of ivermectin vs. albendazole in the presumptive treatment of strongyloidiasis in immigrants to the United States. Epidemiol Infect 132: 1055-1063.

13. Muennig P, Pallin D, Sell RL, Chan MS, 1999. The cost effectiveness of strategies for the treatment of intestinal parasites in immigrants. N Engl J Med 340: 773-779.

14. Grosse SD, Do TQN, Vu M, Feng LB, Berry JG, Sawicki GS, 2018. Healthcare expenditures for privately insured US patients with cystic fibrosis, 2010-2016. Pediatr Pulmonol 53: 1611-1618.

15. Moser W, Schindler C, Keiser J, 2019. Drug combinations against soil-transmitted helminth infections. Adv Parasitol 103: 91-115.

16. Adegnika AA et al., 2014. Randomized, controlled, assessor-blind clinical trial to assess the efficacy of single- versus repeateddose albendazole to treat ascaris lumbricoides, trichuris trichiura, and hookworm infection. Antimicrob Agents Chemother 58: 2535-2540.

17. Welch BL, 1947. The generalization of 'Student's' problem when several different population variances are involved. Biometrika 34: 28-35.

18. Medical Expenditure Panel Survey, 2020. Using Appropriate Price Indices For Analyses of Health Care Expenditures or Income Across Multiple Years. Available at: https://meps.ahrq.gov/ about_meps/Price_Index.shtml. Accessed April 14, 2020.

19. Grant K, 2017. Why world-beating trapical drugs are so hard to get in Canada. The Globe and Mail. Available at: https:// www.theglobeandmail.com/news/national/why-world-beatingtropical-drugs-are-so-hard-to-get-incanada/article33469954/. Accessed May 4, 2020.

20. Georgia Department of Community Health, 2019. Georgia Medicaid Fee-for-Service Anthelmintics PA Summary. Available at: https://dch.georgia.gov/document/document/anthelmintics/ download. Accessed April 20, 2020. 